\title{
EXPERIMENTAL DATA FOR THE CALIBRATION OF A NON- LINEAR NUMERICAL MODEL FOR DESCRIBING THE RESPONSE OF MASONRY CONSTRUCTIONS UNDER CYCLIC LOADING
}

\author{
ANNA CASTElLANO ${ }^{1}$, AGUINALdO FRADDOSIO ${ }^{2}$, MARIO D. PICCIONI ${ }^{2}$, \\ ELEONORA RICCI ${ }^{2 *}$ AND ELIO SACCO ${ }^{3}$ \\ ${ }^{1}$ Department of Mechanics, Mathematics and Management (DMMM) \\ Polytechnic University of Bari \\ Via Orabona 4, 70125 Bari, Italy \\ e-mail: anna.castellano@poliba.it \\ ${ }^{2}$ Department of Civil Engineering Sciences and Architecture (DICAR) \\ Polytechnic University of Bari \\ Via Orabona 4, 70125 Bari, Italy \\ email: \{aguinaldo.fraddosio, mariodaniele.piccioni\}@poliba.it, el.ricci@libero.it (*corresponding \\ author)
${ }^{3}$ Department of Structures for Engineering and Architecture (DiSt)
University of Naples Federico II
Via Claudio 21, 80125 Naples, Italy
email: elio.sacco@unina.it

Keywords: Masonry, Arch, Alternate loading, Stiffness degradation, Experimental.

\begin{abstract}
One of the crucial issues in the still open problem of seismic analyses of masonry constructions is the study of the structural capacity for cyclic loadings; the difficulties are even more pronounced when constructions embedding curved elements like arches, vaults and domes have to be studied. In order to develop effective nonlinear numerical models, the latter have to be capable of representing the relevant aspects of the experimental behavior, and the mechanical parameters of the model have to be carefully calibrated with reference to suitable experimental test results. In this paper the outcomes of experimental tests on a tuff masonry arch under cyclic loading are proposed and discussed, along with the results of experimental tests on the masonry materials (blocks and mortar) aimed at determining the compressive, flexural and shear behavior.
\end{abstract}

\section{INTRODUCTION}

Unreinforced masonry constructions are a large part of the building heritage and are often characterized by a high cultural and historical value. The catastrophic effects of recent earthquakes have highlighted the vulnerability of those construction, and the global relevance of developing suitable approach for the structural analysis under seismic loads.

In this vein, one of the crucial issues in the still open problem of seismic analyses of 
masonry constructions is the study of the structural capacity for cyclic alternate loadings [1]. Indeed, because of the very low tensile strength of mortar joints, the mechanical response of masonry constructions under dynamic alternate loads is strongly influenced by the activation of rocking mechanisms between ashlars, and this behavior is very difficult to predict by using numerical models. On the other hand, rocking mechanisms allow for avoiding the collapse of the structure and make overall the structure capable of withstanding horizontal accelerations considerably higher than those predictable by static non-linear analyses [2].

The problem is even more challenging when curved structural elements like arches, vaults and domes are embedded in the construction. Indeed, in recent years a strong research effort has been made towards the development of numerical models aimed at representing the seismic response and or at least the seismic capacity of masonry constructions including arches, vaults and domes.

The problem is still open, and this is testified by the very different approaches proposed in the literature [3], ranging from nonlinear finite element modeling, where the description of the damage plays a crucial role $[4,5]$, to discrete element modeling $[6,7]$. Other approaches are focused on the determination of estimates of the seismic capacity of curved masonry structures by applying the lower bound theorem [8-10] or the upper bound theorem of limit analysis $[11,12]$.

From the experimental side, whereas recently several very complex full-scale experiments on masonry arches and vaults appeared in the literature (see, e.g., $[13,14]$ ), only a few study the structural response under seismic or cyclicloading. This is due to the intrinsic difficulties of performing these tosts the possible dispersion defects of the constructio Among the few pape results of dynamic and cyclic load experim related numerical modeling issues by applying a nonlocal damage-plastic constitutive law

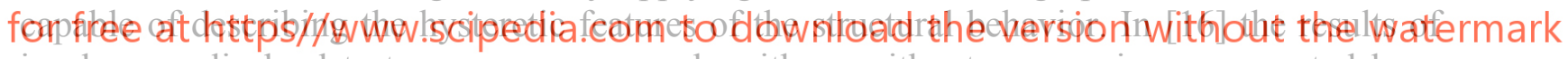
in-plane cyclic load tests on masonry panels with or without an opening surmounted by a masonry arch are presented, highlighting the higher ductility of the arched panel and studying the stiffness, the strength and the energy dissipation under increasing loads. Moreover, in [17] the results of dynamic tests on unreinforced and FRCM reinforced full-scale masonry arches are proposed, bringing out the peculiar dynamic behavior that can be described as a four link "rocking arch" mechanism and discussing the amplification of the base excitation made by the structure.

In this paper the results of an experiment on a masonry arch under a concentrated eccentric cyclic load applied in displacement control are discussed in view of characterizing an innovative cohesive-frictional interface model for describing the non-linear response of masonry constructions recently proposed in [18] by some of the authors.

In particular, the examined masonry arch is made of voussoirs of Apulian tuff jointed by hydraulic lime-pozzolan mortar, as it is usual in the construction of the architectural heritage of Apulia. Masonry materials have been characterized in terms of compressive strength (also flexural strength for the mortar) and of shear behavior, by means of shear tests on triplets, aimed at investigating interface behavior of mortar joints.

The overall structural behavior observed shows a number of aspects relevant especially in 
view of seismic analyses, to be considered in order to correctly calibrate the mechanical parameters numerical of the model. Among them, the progressive damage and the ductility of the structure.

\section{EXPERIMENTAL SETUP}

The experimental test here described was performed on a circular arch made of 15 trapezoidal blocks of Apulian tuff. The arch has an internal radius of $800 \mathrm{~mm}$, an external radius of $1040 \mathrm{~mm}$ and a thickness of the blocks orthogonally to the plane of the arch is of $140 \mathrm{~mm}$ (see Figure 1a).
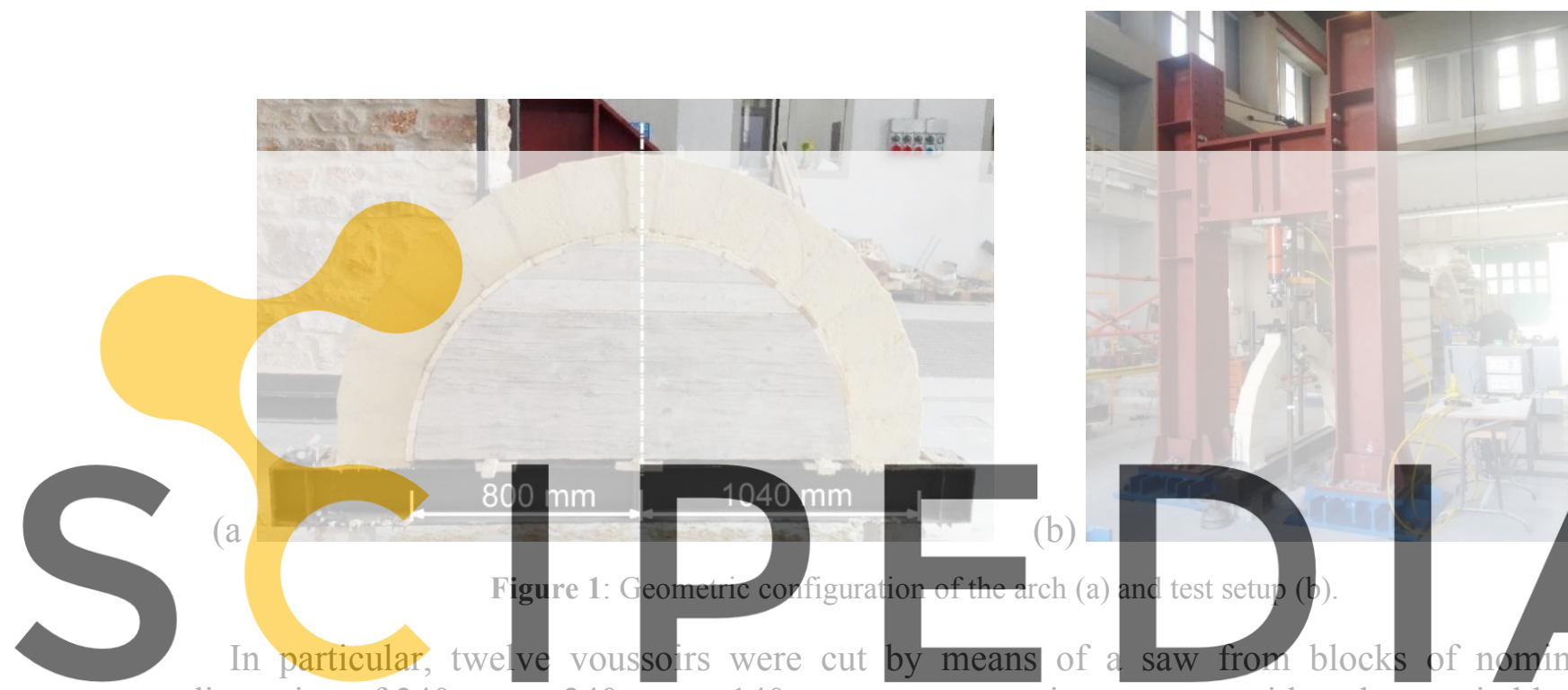

dimension of $240 \mathrm{~mm}$ x $240 \mathrm{~mm}$ x $140 \mathrm{~mm}$; two voussoirs were cut with a shape suitable to

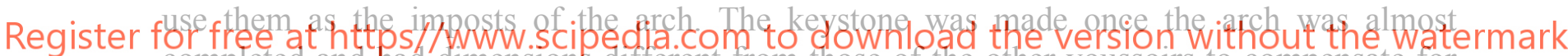
completed and had dimensions different from those of the other voussoirs to compensate for

the imperfections due to the cut and to the mortar joint thickness. On the second tuff block

starting from the keystone a wedge of mortar was made to compensate the inclination of the block due to the arch curvature and provide a support for the loading device (see Figure $2 b$ ). The mortar joints have an average thickness of $1 \mathrm{~cm}$.

After about 1 month since the construction, when mortar joints were perfectly hardened, the steel beam used as the arch basis was moved and placed under a steel frame used for supporting the loading device (see Figure 1b).

Here, the arch was subjected to a concentrated vertical load applied at about one fourth of the span, on a steel plate mounted on the top of the mortar wedge showed in Figure $2 \mathrm{~b}$. The test was carried out under load control, by performing n. 11 load-unload cycles with progressively increasing displacements of the loaded point. At each cycle a visual inspection was also performed in order to identify eventual cracks in the joints, the formation of eventual hinges and, in this case, to measure the opening of the hinges. The load was applied very slowly using a hydraulic jack with a maximum capacity of $500 \mathrm{kN}$, fixed on a rigid contrast beam, shown in Figure 1b. A small load cell with a capacity of $5 \mathrm{kN}$ has been put between the ball joint of the hydraulic and the wedge on the arch (see Figure 2b). 
Six LVDT displacement transducers were used to measure vertical and horizontal displacements. The signal was acquired with a data acquisition system HBM $\mathbb{C}$ MGCplus device.

)
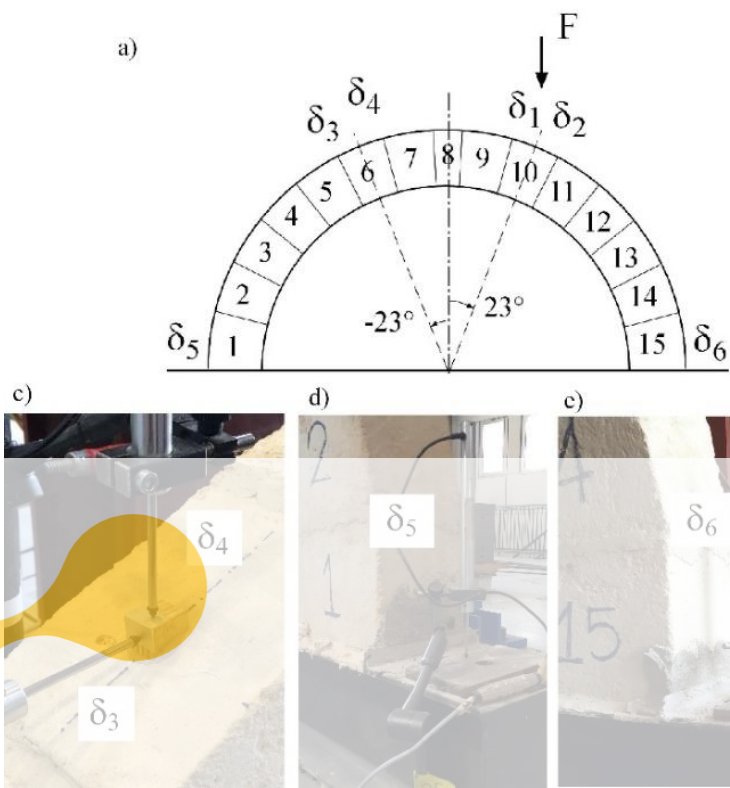

b)

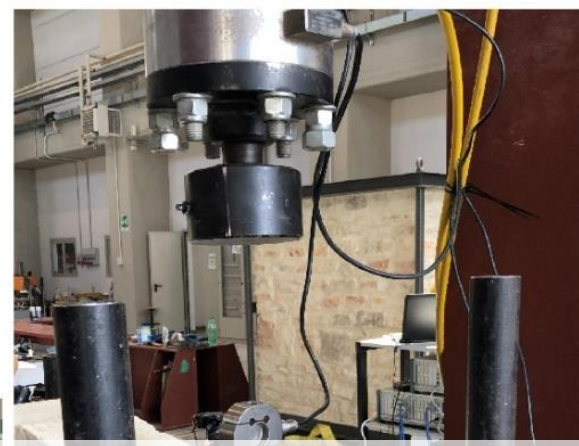

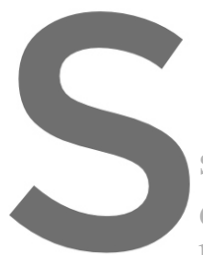
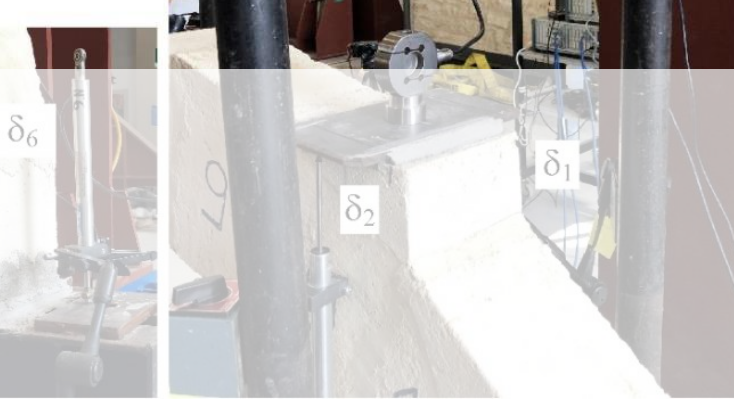

\section{In particular, a \\ In particular, as showed in Figure 2, two \\ span on both sides of th \\ displacements, $\delta_{1}$ and $\delta_{2}$ \\ (Figure \\ e 2b). Other}
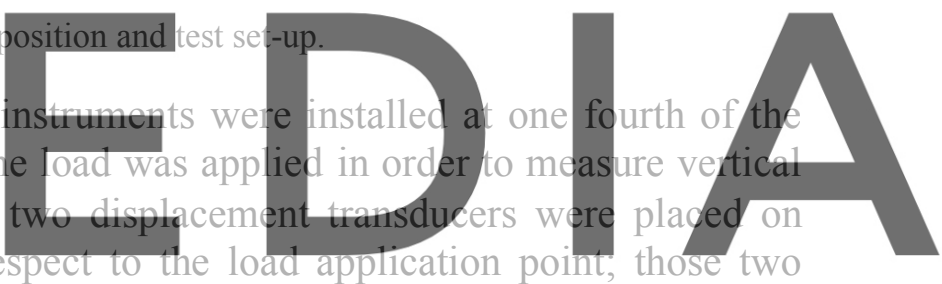

instruments measured both horizontal and vertical displacements, $\delta_{3}$. and $\delta_{4}$ respectively, of

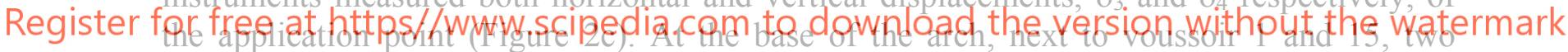

displacement transducers were put to monitor eventual vertical rigid displacements of the support beam, called $\delta_{5}$ and $\delta_{6}$, respectively (Figure $2 \mathrm{~d}$ and $2 \mathrm{e}$ ). In Figure $2 \mathrm{a}$ the location of the LVDT displacement transducers is reported indicating also the angle $\left( \pm 23^{\circ}\right)$ with respect to the vertical axis of symmetry of the arch.

In order to carry out a displacement control test, the oil pressure in the hydraulic jack was constantly adjusted by a feedback system managed by a Labview software. This way the load, measured by the load cell, was promptly adjusted in order to realize the desired target displacement. The very low speed of the test (about $5 \cdot 10^{-3} \mathrm{~mm} / \mathrm{s}$ ) was fundamental in order to avoid undesired effects related to the use of a hydraulic instrument in applying the load.

\section{MECHANICAL CHARACTERIZATION OF THE COMPONENTS}

\subsection{Compressive and flexural behavior}

A mechanical characterization of the masonry components (tuff bricks and mortar) was performed. 
In particular, the compressive strength and Young modulus of the tuff bricks was investigated according to UNI EN 772-1:2011 and UNI EN 1926:2007. Six blocks of Apulian tuff of nominal dimensions of 430x240x150 $\mathrm{mm}^{3}$ and average mass density of $1400 \mathrm{~kg} / \mathrm{m}^{3}$ were tested under compression using a Metro Com universal testing machine with a load capacity of $600 \mathrm{kN}$. Those tests provided an average value of the compressive strength of 2.25 $\mathrm{MPa}$ and average value of the Young modulus of $637.39 \mathrm{MPa}$.

The hydraulic lime-pozzolan mortar used for the joints was made by Mapei ("MapeAntique Allettamento") and is characterized by a mass density of $1883.98 \mathrm{~kg} / \mathrm{m}^{3}$. The compressive and flexural strength were measured according to UNI EN1015-11:2007. The three-point bending test was performed on four 40x40x160 mm mortar prisms after 28 days of curing using an INSTRON 5689 universal with load capacity of $50 \mathrm{kN}$. The average value of flexural strength was determined equal to $1.91 \mathrm{MPa}$. Compression strength tests were carried out on the half prisms, giving an average value of the compressible strength of $8.94 \mathrm{MPa}$. The average value of the mortar Young modulus is $6902.27 \mathrm{MPa}$.

\section{In the main results are reported in Table 1.}

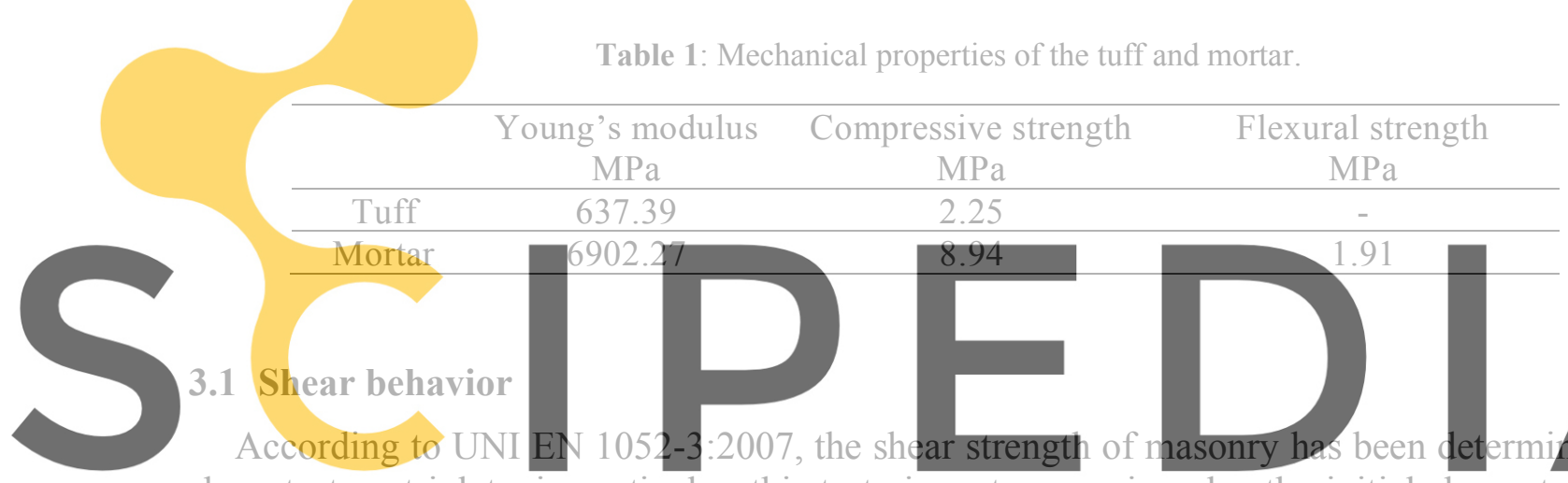

shear test on triplets; in particular, this test aims at measuring also the initial shear strength,

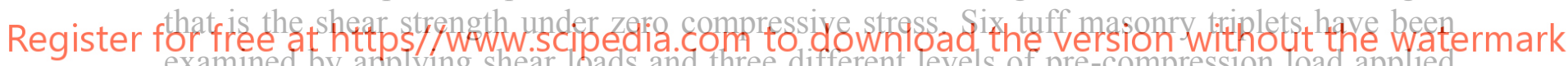
examined by applying shear loads and three different levels of pre-compression load applied normal to bed joint.

During the tests, for each sample (three triplets samples for each pre-compression load), the maximum shear strength $f_{v, i}$ was determined as follows:

$$
f_{v, i}=\frac{F_{i, m a x}}{2 A_{i}}
$$

where $F_{i, m a x}$ is maximum shear load at failure and $A_{i}$ is the bed joint area of each sample. The characteristic shear strength $\mathrm{f}_{\mathrm{vk}}$ was determined as:

$$
\mathrm{f}_{\mathrm{vk}}=0.7 \cdot \mathrm{f}_{\mathrm{v}}
$$

with $f_{v}$ the average shear strength value. Four typical shear failure modes can be observed [19]:

A. a fracture plane localized at one mortar-brick interface due to the attainment of the bonding limit value between the brick and the mortar bed;

B. a vertical crack in the mortar;

C. a fracture plane through a brick; 
D. a failure by crushing and/or splitting due to a similar shear strength of both materials, so that the collapse surface cross both the mortar bed and bricks.

Masonry triplets were made by three hand-cut prismatic bricks with a dimension of 240 $\mathrm{mm} \times 240 \mathrm{~mm} \times 245 \mathrm{~mm}$, jointed by two mortar layers $10 \mathrm{~mm}$ thick; the overall dimension of each triplet was $740 \mathrm{~mm} \times 240 \mathrm{~mm} \times 245 \mathrm{~mm}$. The triplets were tested after curing of 28 days.

The amount of the normal pre-compressive load, applied during the tests by using an independent horizontal actuator (Figure 3a), was identified as a suitable fraction of the compressive strength of the tuff bricks. In particular, the shear tests have been performed with the following levels of the normal pre-compression $\sigma_{\mathrm{p}}$ : $0.1 \mathrm{MPa}, 0.2 \mathrm{MPa}$ and $0.3 \mathrm{MPa}$.

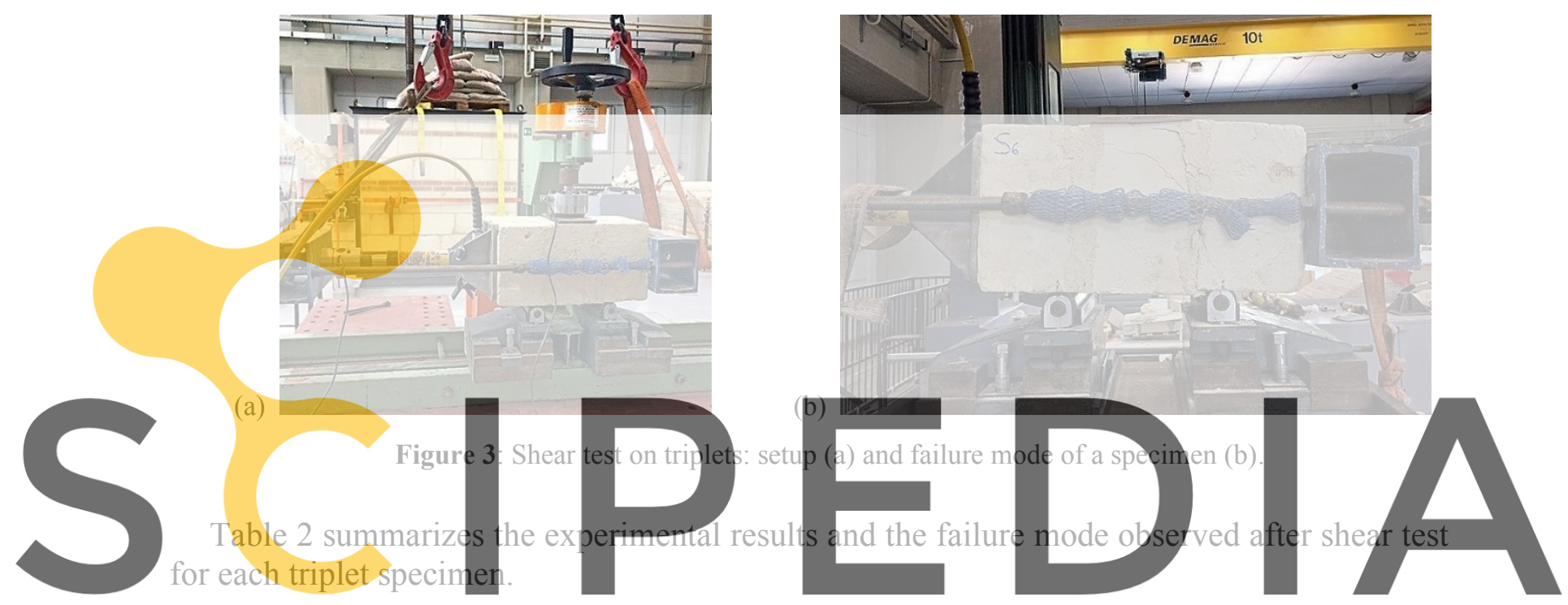

Register for free at https//www.scipedia.com to download the version without the watermark

\begin{tabular}{ccccc}
\hline ID & $\sigma_{p}(\mathrm{MPa})$ & $\mathrm{F}_{\mathrm{i}, \max }(\mathrm{kN})$ & $\mathrm{f}_{\mathrm{v}, \mathrm{i}}(\mathrm{MPa})$ & Failure mode \\
\hline 1__ & 0.1 & 29.3 & 0.249 & $\mathrm{~A}$ \\
\hline 1_2 & 0.1 & 24.2 & 0.206 & $\mathrm{~A}$ \\
\hline 2_1 & 0.2 & 38.9 & 0.331 & $\mathrm{~A}$ \\
\hline 2_2 & 0.2 & 42.9 & 0.365 & $\mathrm{~A}$ \\
\hline $3 \_1$ & 0.3 & 45.3 & 0.385 & $\mathrm{~A}$ \\
\hline 3_2 & 0.3 & 55.8 & 0.474 & $\mathrm{~A}$ \\
\hline
\end{tabular}

The only shear failure mode occurred was mode A, involving decohesion along the interface between tuff brick and mortar (Figure 3b).

Starting from the data in Table 2, the characteristic shear strength $f_{\mathrm{vk}}$ equal to $0.234 \mathrm{MPa}$ has been determined.

Moreover, by plotting the experimental results in the $\sigma_{\mathrm{p}}-f_{\mathrm{v}}$ plane (see Figure 4 ), and by using a linear regression of data, the shear stress with zero normal pre-compression load $f_{v 0}$ and the friction coefficient $\mu$ by means of Mohr-Coulomb failure criterion:

$$
\mathrm{f}_{\mathrm{v}}=\mathrm{f}_{\mathrm{v} 0}+\mu \sigma_{\mathrm{p}}
$$


have been determined. In particular, it results $\mu=1.0119$ and $\mathrm{f}_{\mathrm{v} 0}=0.1327 \mathrm{MPa}$.

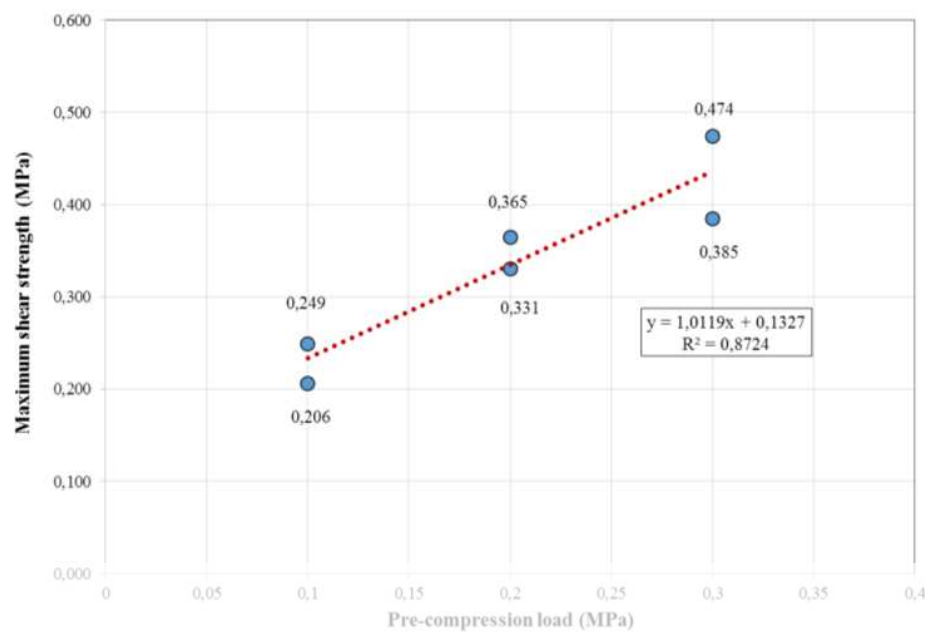

Figure 4: Results of shear test on triplets: shear stress vs pre-compression stress.

\section{CYCLIC LOAD TESTS ON MASONRY ARCH}

In this section the results obtained for the tested arch are described and analyzed. The

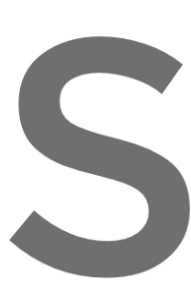
experimental test has

formed a mechanism

classic one, with the for

extrados (see Figure 6 ).

In Figure 5 the obs

load-displacement curves obtained in the

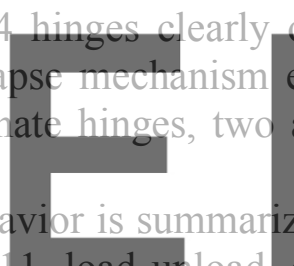

displacement refer to the load application point and it is obtained by averaging the measures

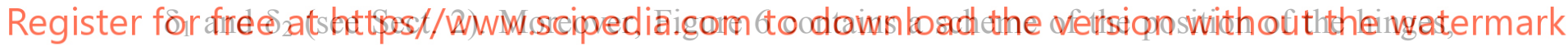
numbered in order of appearance.

As the load cycles progress, the first joint opening has been observed at the intrados under the application point of the concentrated load, that is, between the voussoirs 9 and 10, during the sixth cycle (C6); this corresponds to the opening of and hinge having the center at the extrados in the position $\mathrm{H}_{1}$ indicated in Figure 6. Then, in the same load cycle $\mathrm{C} 6$ a second hinge $\mathrm{H}_{2}$ formed at the intrados in a position almost symmetrical with respect to the first hinge $\mathrm{H}_{1}$; the formation of this hinge corresponds to the opening at the extrados of the joint between the voussoirs 4 and 5 . When the second hinge $\mathrm{H}_{2}$ appeared, a slightly decrease of the load was observed as the displacement increases, until the unload process was started. 


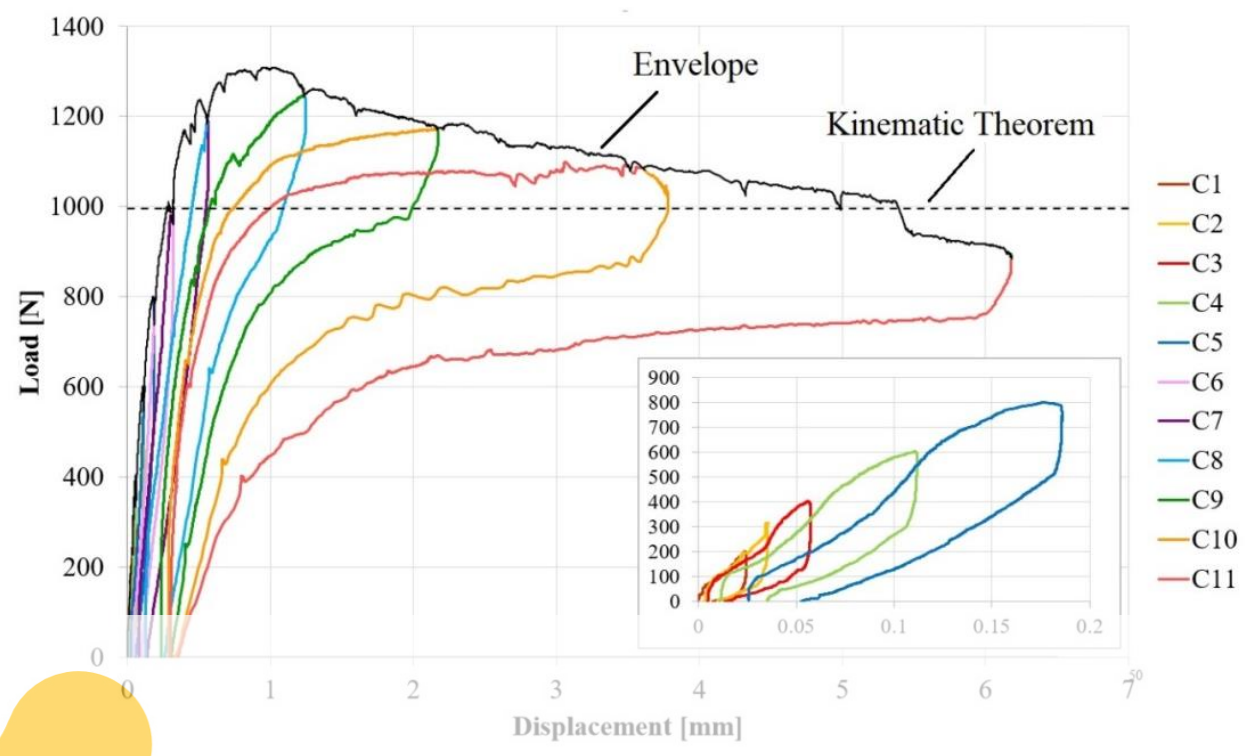

Figure 5: Load-displacement curve and hinge sequence.

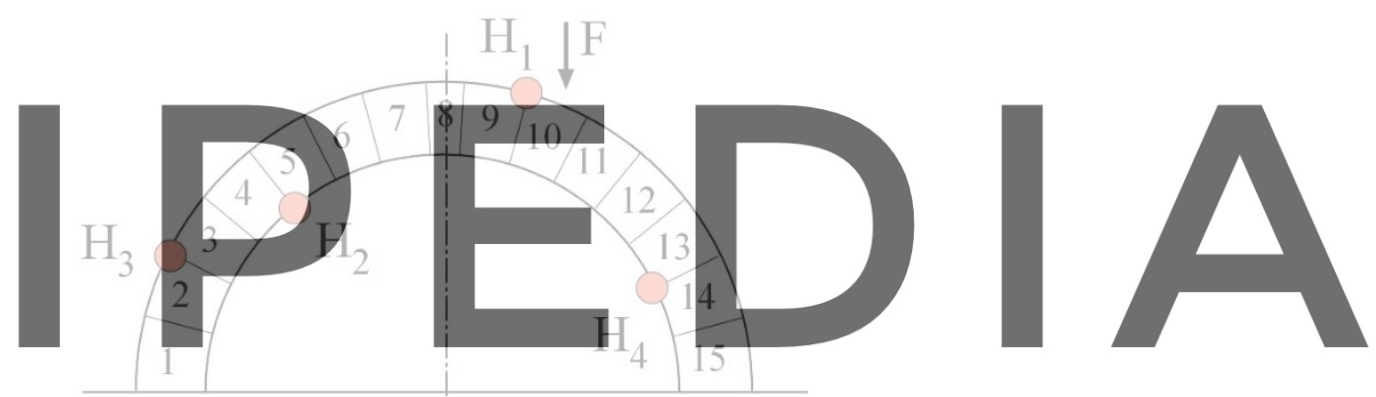

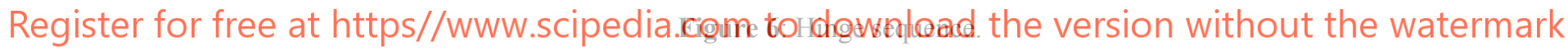

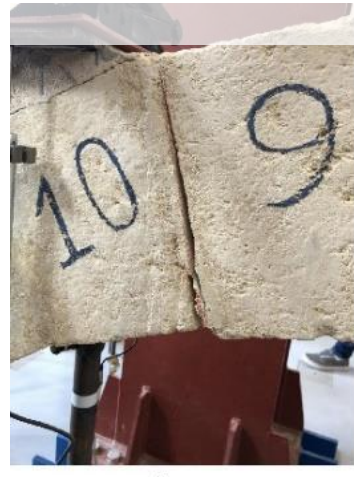

a)

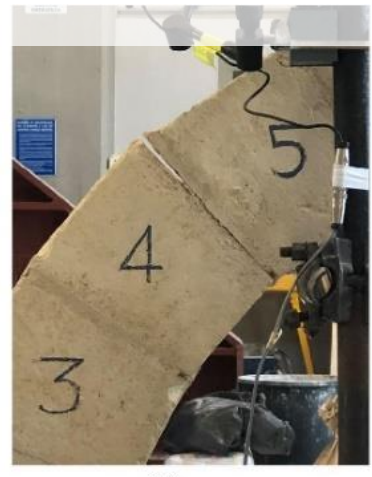

b)

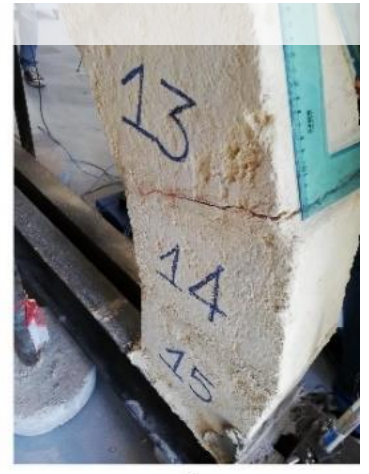

c)

Figure 7: a) First hinge; b) second hinge; c) fourth hinge.

During the seventh cycle (C7) the opening of the joints between the voussoirs 9-10 and 45 , corresponding to the opening of the hinges $\mathrm{H}_{1}$ and $\mathrm{H}_{2}$, was again observed (see Figure $7 \mathrm{a}$ and $b$ respectively); moreover, in correspondence of a load of approximately $1210 \mathrm{~N}$, new 
fractures occurred between the voussoirs 2-3 and 13-14 (see Figure 7c), perfectly symmetrical one another: thus, also the hinges $\mathrm{H}_{3}$ and $\mathrm{H}_{4}$ indicated in Figure 6 formed.

At the peak load of the eighth cycle (C8), equal to about $1310 \mathrm{~N}$, all the above described 4 hinges opened. Figure 5 reports also the collapse load $(995.2 \mathrm{~N})$ determined by the kinematic theorem of limit analysis according to the classical Heyman hypotheses: as it is expected, this load is quite similar to the post-peak load in the last cycle, when it is reasonable to assume that the tensile strength of masonry has been practically cancelled by the damage.

Table 3: Maximum load, displacement corresponding to the maximum load, residual displacement and stiffness for each cycle.

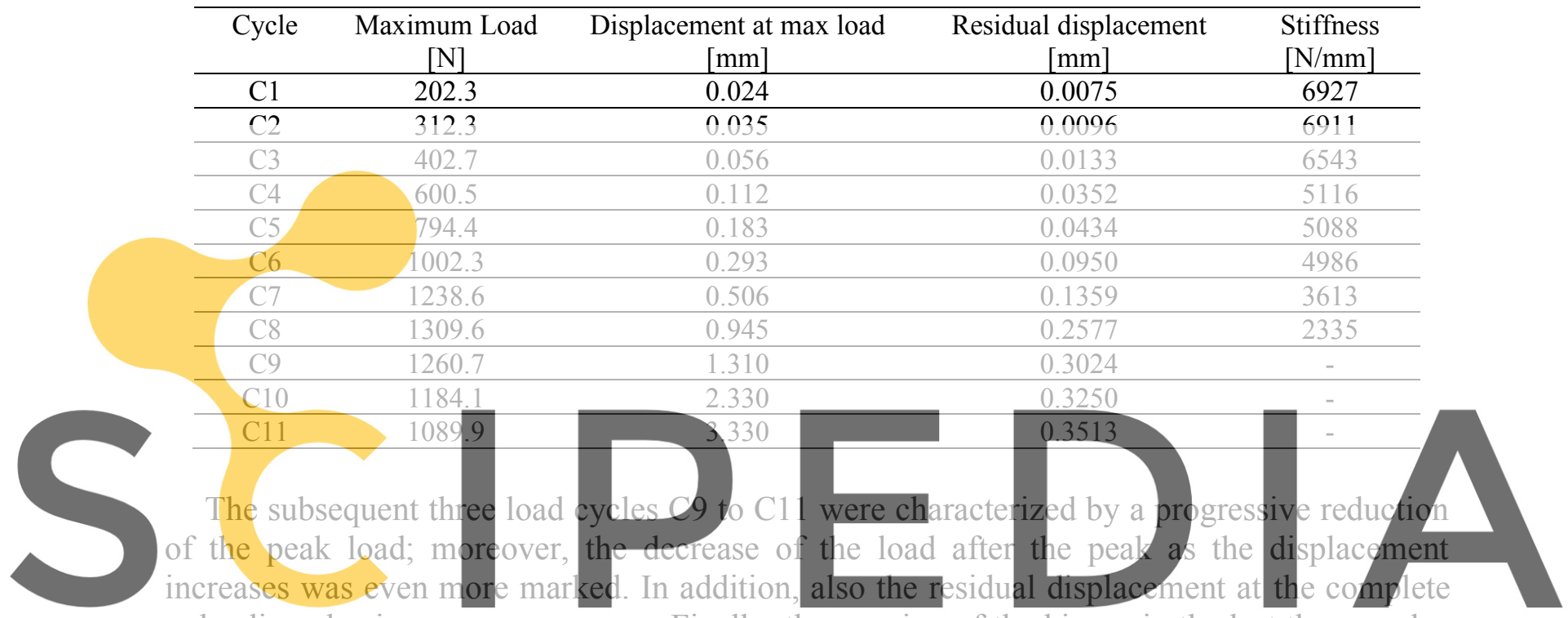
unloading also increases even more. Finally, the opening of the hinges in the last three cycles

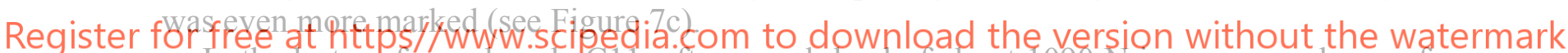
In the last performed cycle C11, after a peak load of about $1090 \mathrm{~N}$ in correspondence of a displacement of $3.330 \mathrm{~mm}$ of the loaded point, the test was pushed up a displacement of about $6.2 \mathrm{~mm}$, and a decrease of the load up to $940 \mathrm{~N}$ was observed. At this point, the test was stopped because it was clear from the progress of the load-displacement curve that for further increase of the displacement the arch would have collapsed.

In Table 3 a synopsis of the main experimental results obtained from the test is reported, including maximum loads, the correspondent displacement of the loaded point, the residual displacements at complete unloading and initial stiffness for each cycle. The latter was evaluated for each cycle with reference to the loading phase before the peak load, by evaluating the best fitting linear approximation to the load-displacement curve between about $25 \%$ and $75 \%$ of the peak load.

Notice that since at the cycle C8 the arch already turned in to a mechanism with the formation of all the 4 hinges above described, the initial stiffness was not determined for the last three cycles. 


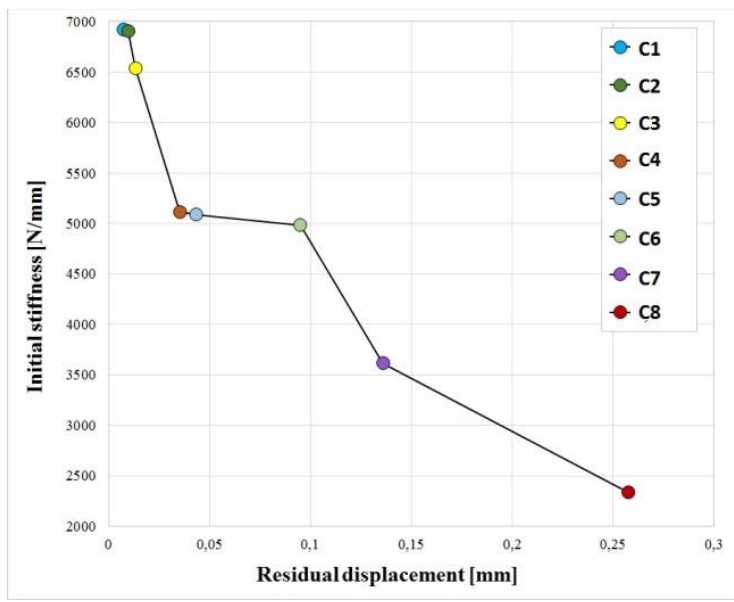

Figure 8: Initial stiffness-residual displacement curve.

In Figure 8 the stiffness values up to the cycle C8 are plotted versus the residual displacement at the complete unloading. The stiffness is practically the same for the first two cycles, correspondingly, the residual displacement is negligible. A sudden decrease of stiffness is noted at the fourth cycle $\mathrm{C} 4$, and this corresponds to a jump of the residual displacement from 0.013 to $0.035 \mathrm{~mm}$. This behavior can be ascribed to the formation of some cracks at the joints that involves irreversible deformations and damage with decrease of

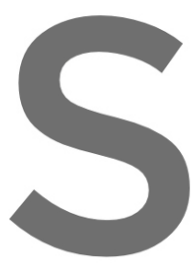
the stiffness. It is likely occurred, whereas at the unload cycle visual noticed only during the From $\mathrm{C} 4$ to $\mathrm{C} 6$ the stiffness remains almost
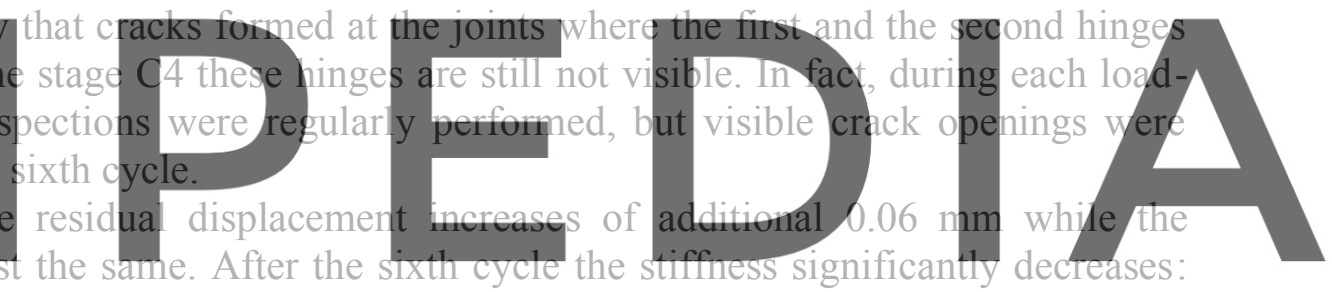

this indicates the progression of the opening of the joints. The residual displacement reaches a

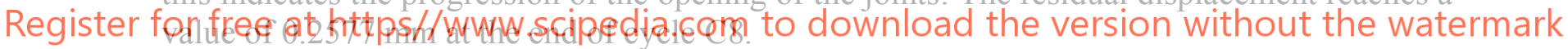

Beyond cycle C8 the load-displacement curves indicate a further decrease of the stiffness of the arch and an additional accumulation of inreversible deformations, denoted by the increase of the residual displacement at the complete unloading.

\section{DISCUSSION AND CONCLUSION}

The results of the performed experimental test show some peculiar feature of the behavior of masonry arch under cyclic loadings, relevant in view of the modeling of the response of masonry structures embedding arches under seismic loadings.

First, that the stiffness of the arch is constant only for low loads; indeed, as the load increases, the compaction of mortar in the bed joints and the opening of cracks at the joints deteriorate the stiffness, that approaches very low values especially in view of the collapse. This pronounced damage effect is relevant as for the case of masonry panels [20].

A second important aspect is that a masonry arch can sustain cyclic loading even beyond the peak load, and that the softening phase is very progressive, without a marked drop of the load capacity. Moreover, the experimental response highlighted a marked ductility, despite to the fragility of the material components (tuff bricks and mortar): this is due to the particular 
arrangement of the masonry, and in particular to the role of the joints, even more relevant in case of masonry curved structures, such as arches and vaults, where the damage localizes practically only in correspondence of the joints.

Furthermore, it should be noted the relatively low value of permanent displacements after the complete unloading, even in the proximity of the collapse, and the narrow shape of the hysteretic loops, indicating the quite low energy dissipation related to the cyclic opening and closing of the hinges.

All the above aspects are very challenging to be modeled and requires nonlinear numerical models capable of accurately describing the damage and the peculiar features of the unloading phase, like the model proposed in [18].

Notice that in the experiment on the arch the shear strength of the interface is never called into play, but its careful characterization is important for describing other kind of structures, like, e.g, a masonry wall even if embedding and arch. In addition, notice that whereas no direct tests have been performed for determining the tensile strength of the masonry, this mechanical parameter can be calculated starting from the cohesion evaluated in shear tests for zero pre-compression stress.

In the next future, the latter will be calibrated starting from the experimental outcomes here described, and then employed for performing non-linear numerical analysis of a masonry wall including both small rectangular openings representing windows recesses and a large opening topped by a masonry arch representing the main door entrance. In particular, the influence of interfacial shear strength of masonry joints on the overall behavior of the masonry structure will be analyzed by a parametric study. Moreover, also FRCM reinforced arches will be taken into account, were an accurate description of the shear behavior of the interfaces play an important role.

\section{REFERENCES}

[1] Mallardo, V., Malvezzi, R., Milani, E. and Milani, G. Seismic vulnerability of historical masonry buildings: A case study in Ferrara. Eng. Struct. (2008) 30(8):2223-2241.

[2] Lagomarsino, S. Seismic assessment of rocking masonry structures. B. Earthq. Eng. (2015) 1: 97-128.

[3] D’Altri, A.M., Sarhosis, V., Milani, G., Rots, J., Cattari, S., Lagomarsino, S., Sacco, E., Tralli, A., Castellazzi, G. and de Miranda, S. Modeling Strategies for the Computational Analysis of Unreinforced Masonry Structures: Review and Classification. Arch. Comput. Method E. (2019) https://doi.org/10.1007/s11831-019-09351-x.

[4] Pelà, L., Cervera, M. and Roca, P. An orthotropic damage model for the analysis of masonry structures. Constr. Build. Mat. (2013) 41:957-967.

[5] Addessi, D., Marfia, S., Sacco, E. and Toti, J. Modeling approaches for masonry structures. Open Civil Eng. J. (2014) 8(1):288-300.

[6] Lemos, J.V. Discrete element modeling of masonry structures. Int. J. Archit. Herit. (2007) 1(2):190-213.

[7] DeJong, M.J., De Lorenzis, L., Adams, S. and Ochsendorf, J.A. Rocking stability of 
masonry arches in seismic regions. Earthq. Spectra (2008) 24(4):847-865.

[8] Fraddosio, A., Lepore, N. and Piccioni M.D. Lower Bound Limit Analysis of Masonry Vaults Under General Load Conditions. In: R. Aguilar et al. (Eds.): Structural Analysis of Historical Constructions, RILEM Bookseries 18 (2019), pp. 1090-1098.

[9] Ricci, E., Fraddosio, A., Piccioni M.D. and Sacco, E. A new numerical approach for determining optimal thrust curves of masonry arches. Eur. J. Mech. A-Solid (2019) 75: 426-442.

[10] Fraddosio, A., Lepore, N. and Piccioni M.D. Thrust Surface Method: An innovative approach for the three-dimensional lower bound Limit Analysis of masonry vaults. Eng. Struct. (2020) 202:109846.

[11] Milani, G. and Lourenço, P.B. 3D non-linear behavior of masonry arch bridges. Comput. Struct. (2012) 110-111:133-150.

[12] Chiozzi, A., Milani, G. and Tralli, A. A Genetic Algorithm NURBS-based new approach for fast kinematic limit analysis of masonry vaults. Comput. Struct. (2017) 182:187-204.

[13] De Santis, S., Roscini, F. and de Felice G. Full-scale tests on masonry vaults strengthened with Steel Reinforced Grout. Compos. Part B-Eng. (2018) 141:20-36.

[14] Bove, M., Castellano, A., Fraddosio, A., Scacco, J., Milani, G. and Piccioni M.D. Experimental and numerical analysis of FRCM strengthened parabolic tuff barrel vault. In: A. Di Tommaso et al. (Eds.): Mechanics of Masonry Structures Strengthened with Composite Materials III, Key Engineering Materials 817 (2019), pp. 213-220.

[15] Toti, J., Gattulli, V. and Sacco, E. Damage propagation in a masonry arch subjected to slow cyclic and dynamic loadings. Frattura integr. strutt. (2014) 29:166-177.

[16] Karimi, A.H., Karimi, M.S., Kheyroddin, A. and Shahkarami A.A. Experimental and Numerical Study on Seismic Behavior of An Infilled Masonry Wall Compared to An Arched Masonry Wall. Structures (2016) 8:144-153.

[17] Castellano, A., Fraddosio, A., Scacco, J., Milani, G. and Piccioni M.D. Dynamic response of FRCM reinforced masonry arches. In: A. Di Tommaso et al. (Eds.): Mechanics of Masonry Structures Strengthened with Composite Materials III, Key Engineering Materials 817 (2019), pp. 285-292.

[18] Serpieri, R., Albarella, M. and Sacco E. A 3D microstructured cohesive-frictional interface model and its rational calibration for the analysis of masonry panels. Int. J. Solids Struct. (2017) 122-123:110-127.

[19] Abdou, L., Ami Saada, R., Meftah, F. and Mebarki, A. Experimental Investigations of the Joint-Mortar Behaviour. Mech. Res. Commun. (2006) 33:370-384.

[20] Rinaldin, G., Amadio, C. and Gattesco, N. Review of experimental cyclic tests on unreinforced and strengthened masonry spandrels and numerical modelling of their cyclic behavior. Eng. Struct. (2017) 132:609-623. 